ARTICLE

https://doi.org/10.1057/s41599-019-0357-z

\title{
Unveiling pathways for the fissure among secessionists and unionists in Catalonia: identities, family language, and media influence
}

\author{
José M. Oller (iD ${ }^{1}$, Albert Satorra ${ }^{2} \&$ Adolf Tobeña (iD ${ }^{3 *}$
}

\begin{abstract}
Catalonian secessionism acquired prominence from 2010 onwards. During the last decade secessionist parties won three regional elections and sustained Governments by tiny majorities at the Autonomous Parliament. Two illegal consultations about selfdetermination were called and around 2 million (38\% of population census) supported secession from Spain. An "Independence Declaration" was proclaimed on 27th Oct. 2017, followed by suspension of Home Rule sanctioned by Spanish Parliament that endured till mid2018. The main consequence of the secessionist push was the build-up of a confrontation between two large segments of Catalan citizenry, unionists and secessionists, which was absent before. This study aims to shed light on the rise of secessionism and the appearance of a deep fissure between these communities. By building upon the complete series of data from iterated official polls (88.538 respondents, 45 surveys), the paper displays the evolving changes along the period 2006-2019 of national identity feelings ("sense of belonging"). Along that period, there were increases exceeding 15 percentage points of "only Catalan" national identity and analogous decreases of "equally Catalan and Spanish" dual national identity. The findings disclosed highly significant covariations between changing trends on national identity feelings with: (1) family/mother language, Catalan vs. Spanish; (2) following regional media versus other media. Since language/ascendancy origins and media consumption trends are closely interrelated, within Catalonia, our discussion focuses on the role played by such ethno-cultural cleavage. Further, statistical analysis for longitudinal data identified several turning points linked to singular political events that likely accentuated polarization around the issue of secession. The findings unveil evolving tracks that could help in the understanding of a process that, in a very short time, produced a severe social division within a fully open and democratic society at the heart of Europe.
\end{abstract}

\footnotetext{
${ }^{1}$ Department of Genetics, Microbiology and Statistics, University of Barcelona, Diagonal 643, 08028 Barcelona, Spain. ${ }^{2}$ Department of Economics and Business, Universitat Pompeu Fabra and Barcelona-GSE, Barcelona, Spain. ${ }^{3}$ Department of Psychiatry and Forensic Medicine, Institute of Neurosciences, Universitat Autònoma Barcelona, 08193-Bellaterra Campus, Cerdanyola, Barcelona, Spain. *email: adolf.tobena@uab.cat
} 


\section{Introduction}

he surge, rapid evolution and failed culmination of the recent secessionist attempt at Catalonia was a unique experiment in contemporary Western politics. It carried characteristic ingredients: (1) gigantic and iterated street demonstrations fueled by an unrelenting and skillful activism; (2) absence of a clear secessionist majority within the region; (3) strong impulse and direction given by a Regional Government and an Autonomous Parliament openly confronting Central Powers; (4) systematic pro-secession bias by public media controlled by Autonomous powers; (5) overwhelming social pressure by a continuous presence of secessionist symbols everywhere; (6) successful silencing of the majoritarian non-secessionist citizenry throughout most of the upsurge (Barrio and Field, 2018; Elliott, 2018). All that arising at one of the richest and more advanced Spanish regions, within a democratic context at the heart of the European Union. The upsurge was an unexpected, enduring and extremely resilient mass movement (Crameri, 2014, 2015) that attracted global media attention (Minder, 2017; Morel, 2018), leaving the Spanish Government paralyzed for years and the European Union perplexed (see at SI, a summary of events and electoral results).

A plethora of interpretations (Amat, 2015, 2017; Barrio and Field, 2018; Barceló-Soler, 2013; Boylan, 2015; Crameri, 2014, 2015; Coll et al., 2018; Cuadras-Morató and Rodon, 2018; Dowling, 2018; Elliot, 2018; Griffiths et al., 2015; Minder, 2017; Morel, 2018; Serrano, 2013), tried to explain the secessionist surge at Catalonia focusing mainly on economic and socio-political issues: a deep economic recession during the preceding years; irritation with malfunctioning and corruption of Spanish parties and institutions; arrogance and passivity of Spain's central government in front of a movement instigated by ambitious and discontent regional elites; weaknesses and inadequacies of the European Union. These factors surely contributed in varying degrees, though they left unexplained why they had uniquely combined within a single European region, to the point of triggering urgent demands for segregation, while similar tensions did not appear in other comparable Southern Europe regions.

Barrio and Field (2018) proposed that the secessionist push was not simply a bottom-up process where malcontent and selforganized citizens increasingly escalated demands for independence. Longitudinal findings had shown that Catalan political elites were more radical than citizens and that outbidding to win hegemony in the pro-secession camp probably fueled the movement (Barrio and Rodríguez-Teruel, 2017). Hence the secessionist surge could have depended also from top-down influences arising from harsh competition between nationalist elites and parties to keep a dominant position within the Region. From such perspective the secessionist wave ("the procés"), was a movement nourished by local elites narrowly intermingled with the Autonomous administration, to take advantage of the "window of opportunity" (Griffiths et al., 2015) opened by the deep economic and political weaknesses of a Spain near bankruptcy, during 2008-2013 period.

The more important consequence of the failed secession venture was the excavation of a deep divide of Catalan society into two confronted communities: secessionists and unionists ${ }^{1}$. The lack of a social majority behind the secessionist attempt opened apprehensions and frictions that had been mostly absent previously (Amat, 2015; Barrio and Field, 2018; Elliot, 2018; Dowling, 2018). Close neighbors, colleagues, acquaintances and even friends and families who had shared feelings of belonging to both Catalonia and Spain (in different degrees), as a part of their values, are now divided on the issue of secession and must endure living together amid an unsolved tension (Amat, 2017; Barrio and Field, 2018; Coll et al., 2018; Elliott, 2018). National identity feelings ("sense of belonging") are a main mediator of the divide between secessionists and unionists (Oller et al., 2019a, 2019b): the first ones declare an almost exclusive emotional/affective identity link with Catalonia, whereas unionists have various communal affects, with a dominant double attachment with Spain-Catalonia (Catspanish). The accentuation of affective features of identity around a specific political divide (accept/reject secession), can reproduce similar paths towards increasing animosity and ruthless partisanship that have characterized recent political struggle at several Western societies (Von Babel and Pereira, 2018). Harsh partisanship between USA democrats and republicans that grew through an increasingly narrow fusion between self and group identities is a prominent example of that (Mason, 2018), and the contemptuous struggle that currently divide Britons on the issue of remaining or leaving the $\mathrm{EU}$ is another one (Golec de Zavala et al., 2017; Zmigrod et al., 2018).

During deep political crises the existence of unsealed ethnocultural cleavages is a widely known pre-requisite to trigger processes of quick polarization between neighboring communities (Horowitz, 2001; Esteban et al., 2012). The ethnolinguistic cleavage that separates the two main Catalonian communities had been highlighted by Miley $(2007,2013)$. The first ones use Catalan language in all domains, whereas the second ones prefer Spanish despite their knowledge of Catalan language ${ }^{2}$. Using survey data from CEO Barometers ${ }^{3}$ after the four Regional elections between 2010 and 2017, Bertomeus (2018) found that Catalan-speaking citizens augmented their support to secessionist parties, whereas Spanish-speaking ones increased their vote for unionist parties in divergent though comparable shifts. OEC Group (2017) had also showed that such tendency towards a stronger political polarization was rooted on the main linguistic divide. Llaneras (2017) added socioeconomic factors to the gap between unionists and secessionists. Secession appealed mostly to native Catalans (CEO Barometer July 2017): it was higher among citizens born in Catalonia and with at least one parent born there, with a maximum (75\%) for those with long native ascendancy. Among citizens coming from abroad or from other Spanish regions, and for those born within the region from migrant parents, secession was not attractive at all. The divide depended also on incomes: secession support predominated among citizens with highest incomes and among those who said: "we live comfortably". On the contrary, most people with the lowest salaries and those disclosing "many economic difficulties" were against secession. Maza et al. (2019) multivariate analysis of voting behavior at the last Regional Elections (21 Dec. 2017), confirmed the priority of ascendancy origins to explain the results, while greatly diminishing the relevance of economic factors. Cuadras-Morató and Rodon (2018) obtained fully concordant results using survey and electoral data, at two time points, and Oller et al. (2019b) as well, in a parallel analysis of the longitudinal data used here.

This ethnocultural cleavage defined a breaking line for the division created by the secessionist campaign (Tobeña, 2017; Barrio and Field, 2018; Elliot, 2018). The divide has not arrived at the threshold of an open violent conflict, though tensions were high during autumn of 2017 and they subsist while the situation remains on a chronic standstill. Frictions are not rare at different social scenarios and keep confronted two communities who had enjoyed a long tradition of tolerant and convivial relationships (Amat, 2015, 2017; Barrio and Field, 2018; Elliot, 2018). There have been worries that such a divide might lead to inter-group clashes that would carry the ingredients that appear in societies sheltering unsealed ethno-cultural frontiers (Esteban et al., 2012; Horowitz, 2001; Lustick et al., 2004; Sidanius et al., 1997; Sorens, 2005; Miley, 2007; Castano, 2008; Qvortrup, 2014; Waytz et al., 2014). 
The present paper aims to shed light on enacting vectors that facilitated the division between the two main communities in Catalonia. We do that by bringing extensive data of surveys collected from 2006 to 2019 by the official Catalan survey agency (CEO Barometer). The longitudinal analyses of variations of the main variable, namely "sense of belonging" feelings (from "Only Catalan" to "Only Spanish" distinctive national identities, as defined through the five categories at the surveys), may add important clues to the unsolved discussion about plausible sources of the building of what is now a souterrain confrontation (Barrio and Field, 2018; Elliott, 2018; Maza et al., 2019; Tormos et al., 2014). We will focus first on variations of sense of belonging feelings in two significant segments of Catalan citizens, those whose family language is Catalan vs. those whose family language is Spanish. This is mandatory since previous findings either from survey data or from electoral results had established the priority of this ethnolinguistic cleavage rooted on ascendancy origins (Cuadras-Morató and Rodon, 2018; Maza et al., 2019; Miley, 2007, 2013; Oller et al., 2019a, 2019b). Secondly, we will assess the evolving changes of sense of belonging depending on media following preferences-whether the official TV and Radio controlled by the Regional Government (broadcasting exclusively in Catalan language), vs. other TV and Radios, because in previous studies we and others had shown the importance of this variable (Garcia, 2013; Tobeña, 2017; Oller and Satorra, 2017; Oller et al., 2019a, 2019b). Since media and language are closely interrelated within the region, our analysis will address an exciting issue, namely the language acting as a protective umbrella from propaganda from the other side.

Through detailed analyses of trend variations of "sense of belonging" (national identity feelings), across the whole development of the secessionist push, we wanted to explore the relevance of some "turning points" linked to recognizable induction events. In this way, we expected to disclose patterns of data which may help to discern between bottom-up vs. top-down pathways about the sources of the conflict. We finally foresee that our detailed, systematic and mostly descriptive/correlational statistical evidence can work as starting point to further searches looking for more fully substantive explanations of this unexpected, serious and stagnated political crises at the heart of Europe.

\section{Methods}

To study the changing evolution of secessionist vs. unionist strength among Catalonian citizenry we worked exclusively with data obtained by C.E.O. Barometers (the official survey agency of the Regional Government), along the period 2006-2019. This data was supplied in open access from March 2006 to the present and includes the totality of biannual/triannual systematic surveys that CEO launches with high regularity. The sample sizes of 45 surveys analyzed oscillated between 2500 and 1500 citizens each, with the exception of autumn 2017 survey which had only 1338 citizens. We had thus a total of 88.538 respondents.

Our research focus (longitudinal opinion trends about the issue of secession) is a multifaceted phenomenon that can be quantified by many variables, among others by "Sense of Belonging" (National Identity Feelings), "Preferences for political links with Spain", "Affirmative/Negative answers on a legal referendum about secession" and others. We selected "National Identity Feelings" as our main target because it was studied in the whole series of CEO surveys and does not depend on changing political labels that may distort the results. Findings on "Preferences for political links between Catalonia and Spain" and explicit "Support/Reject of secession" in a hypothetic referendum of independence are briefly presented as well at Supplementary Information (SI). We explored the relationship between our main variable with others related to the main ethnolinguistic cleavage that characterizes Catalonian citizenry. Specifically, we considered, for each survey, the qualitative variables Family/Mother language and the binary variable Follow news on public regional media (TV or radio, under control of Regional Government) or not, variable that we can refer hereafter as News (See at SI Appendix the Detailed Survey Questions studied).

We were fully aware of the limits and restrictions we adopted in our analyses of an obviously multi-causal phenomenon. Among the 'stories' offered by different options regarding secession, citizens can 'opt' for one of them for many reasons: some related to their entourage-family, friends, co-workers, even their own random histories; others, from current economic hardships or affective/ideological affinities; others from information received through the media or social networks, and so on. Therefore, to be able to discern the causes of the changing trends in this issue, a detailed and systematic follow-up of specific individuals would be necessary, an information that it is not available.

Hence, due to the nature of our data we decided to limit ourselves to study significant stochastic dependencies between variables: just a strictly statistical work (descriptive plus correlational), although it is true that, in this context, high stochastic associations might suggest plausible explanations of the mechanisms that shaped the observed trends. Subsequent explorations of these associations would require accruing other data and other mathematical tools. To our view, the so-called 'statistical causal models' assess 'causal' relationships only under a theoretical frame or hypothesis that are external to statistics. We do not pre-assume a theory, so our emphasis in this paper is to exploit a rich database to unveiling significant associations that should shed light on the plausibility of alternative theoretical frames or hypothesis. Other analysis could be pursued incorporating other type of data, to study the likelihood of alternative explanatory models.

Longitudinal changes of national identity feelings and linguistic groups. We estimated first, the distinctive percentages of "sense of belonging" (national identity feelings), an essential underlying variable of the phenomenon studied, in the overall population and in different family language groups, obtained from survey samples, with some supplied weights if necessary. As already stated the sample sizes of the 45 surveys analyzed oscillated between 2500 and 1500 citizens each (autumn 2017 survey had only 1338 citizens), and we had a total of 88.538 respondents. The standard deviations of conditional distributions (sense of belonging conditioned to family/mother language ${ }^{4}$ ) for samples between 2500 and 1500 for the main population segments $(25 \%$ of the population or more), oscillated from $2.5 \%$ to $1 \%$.

We then plotted the longitudinal changes of national identity feelings between 2006 and 2019 in the overall population distinguishing also by the main family/mother language groups: the Catalan-group (34.9\% was the size of this linguistic group at the last survey, July 2019) and the Spanish-group (57.3\% was its size, at that survey). For the sake of clarity, we decide to plot only the more frequent identity feelings in each linguistic group: people who considered both languages, Spanish and Catalan, as their family/mother languages $(4.1 \%$ was the size of this linguistic group at July 2019 survey) exhibited an intermediate behavior. We added also a smooth $95 \%$ confidence band based on a generalized additive model implemented through the $\mathrm{R}$ package mgcv (Wood et al., 2016; Hastie and Tibshirani, 1990).

Furthermore, in the plots, we marked also historical events that might have been relevant to understand the evolution of the studied variables along the period. These events were: the date 
when a new Home Rule was approved (New Statute); the resolution of the High Spanish Court (Tribunal ConstitutionalTC) that sanctioned 14 articles (over 223) as contrary to the Spanish Constitution and restricted the preamble and another 27 articles (June, 2010); the peak protests of the social $15 \mathrm{M}$ movement (15M Peak Protests, June 2011); the regional elections of November 25, $2012(25 \mathrm{~N})$; the illegal consultation about independence of November 9, $2014(9 \mathrm{~N})$; the regional elections of September 27, 2015 (27S); the illegal referendum about secession, October 1, 2017 (1 Oct) and the regional elections, December 21, 2017 (21D).

Additionally, in order to identify important change points detected in the series, we used the $\mathrm{R}$ package ecp designed for nonparametric multiple change point analysis of multivariate data (James and Matteson, 2013, 2014), which implements a divisive hierarchical algorithm to detect reasonable change points, through a bisection method and a permutation test. We worked at 0.025 significance level and demanding at least six observations, from 1.75 to 2 years, between change points. The change points obtained using this approach are indicated as vertical red lines in the figures. These change points were obtained using the complete profile of national identity feelings of the groups: from those who self-considered Only Spanish to those who selfdiagnosed as Only Catalans, including also the class of DK/NA (do not know or no answer). Hence, they are multivariate results although the series showed the evolution of main profiles of each linguistic group.

Longitudinal changes of national identity feelings, linguistic groups and regional public media. We studied also the evolution of these national identity feelings considering not only family/ mother language but also a dichotomous variable constructed taking into account whether the news were followed or not through regional public media (TV channel TV3, and radio station Catalunya Radio). First, we plotted the evolution of national identity feeling 'Only Catalan' in the four groups of the Catalonian population obtained crossing the two main categories of Family/mother language (Catalan vs. Spanish) with the dichotomous variable News (with also two levels, according to whether the news were followed at regional public media or not). The obtained graphics allow to compare the different evolution of these groups. Secondly, we have obtained the same graphics but with the national identity feeling 'equal Spanish than Catalan' in the same groups as before and comparing their evolution.

We additionally analyzed this data, as an approximation, through the perspective of Analysis of Covariance (ANCOVA). For the sake of simplicity, we started with two ordinary univariate analysis and continued with a combination of them in a bivariate version of MANCOVA, that we shall describe hereafter. At the start, we considered two factors for both analysis whose levels were the different possible values of the qualitative variable family/mother language (with two levels corresponding to the main linguistic groups: Catalan and Spanish) and the dichotomous variable News (with also two levels, according to whether the news were followed at regional public media or not), using Time (from 2006) as a covariate and considering as dependent variable the percentages of those who feel 'only Catalan', for the first analysis, or 'equal Spanish than Catalan', for the second one. Since the interaction between factors was highly significant, to facilitate the analysis we built a new factor, Group, with four levels, combining the two levels of Family/mother language factor and both levels of the factor News. We have used this factor to replace the previously mentioned original binary factors in the final analysis.
Notice that there were two sources of randomness: one corresponding to the sample procedure and another corresponding to the political and communicative events along the period: we used a linear model as a simple way to deal with both sources of variability, just as an approximation, introducing Time (in years, from 2006) to try to capture potential trends and checking the global adequacy of this approach examining the standard output supplied by the function lm of $\mathrm{R}$ package stats. We supply also a graphic plot illustrating the dependence of each percentage ('only Catalan' and 'equal Spanish than Catalan') with respect to Time covariate, in each one of the four levels determined by both factors. We did as well a bivariate version of these analysis, considering both variables. Most of the results of this analysis can be found at SI Appendix.

Finally, also at SI, we supply a summary of relevant percentages of national identity feelings at specific relevant moments: the initial and final values, on the period 2006-2018, and these percentages immediately before and after the regional elections at 25th November 2012 (Table SI-6).

2D dynamic profile diagram. To compare the evolution of the groups obtained considering family/mother language (Catalan vs. Spanish) and whether news were followed or not through the regional public media (Regional vs. Others), we could analyze the plot series of all percentages of "Sense of belonging" for each one of them. These groups would be: A (family/mother language Catalan, following news in public regional media), B (family/ mother language Catalan, not following news in public regional media), C (family/mother language Spanish, following news in public regional media) and D (family/mother language Spanish, not following news in public regional media); but this would have required plotting $4 \times 6=24$ series of distinctive percentages of "Sense of belonging", along the period. We present instead a synthetic two-dimensional Dynamic Profile Diagram (of Sense of Belonging, in this case) through the period 2006 -2019 . Essentially, it is a two dimensional (2D) Multidimensional Scaling (MDS) representation of the abstract space of Sense of Belonging profiles, using the Hellinger distance (Burbea and Rao, 1982). Each one of the four groups, at a particular time, is represented first as a point on the above mentioned (six dimensional) abstract space and then, though the MDS techniques, as a point on a 2D-plot. Since each of these four points are not fixed, they apparently 'move' as Sense of belonging feelings change, then we may connect them in the plot to facilitate viewing the change along time. Therefore, the evolution of profiles at different time points is seen as a continuous broken line, for each group, in the $2 \mathrm{D}$ representation. This graphic provides a simple overall summary of the joint evolution of the various groups. More technical details of this MDS graph can be found at SI.

Other variables. We repeated the analysis on another qualitative variable: Preferences for political link between Catalonia and Spain, whose values indicated preferences for a centralized state (Catalonia as a Region), actual status quo (Home Rule, CA), an explicit federal solution (Federal) or an independent state (Independent Catalonia), considering also DK/NA options. The results come at SI. Furthermore, the positive/negative explicit answers in the event of a hypothetic legal referendum about secession from Spain were also analyzed (see SI). This was a qualitative variable with three possible outcomes: Yes, No and $\mathrm{DK} / \mathrm{NA}$, reproducing the approach and contrasts of the main methods exposed. 
Ethical approval. All the data for this research came from the C. E.O. Barometers, the official survey agency of the Regional Government, complying with the full legal Spanish requirements and restrictions to conduct sociological studies about voting behavior and political opinion, and in accordance to the ESOMAR International Code on Market, Opinion and Social Research and Data Analytics. All the statistical analyses included in this paper fulfilled, in addition, the conditions established by the Ethical Commissions of the University of Barcelona, Pompeu Fabra University and the Autonomous University of Barcelona for treatment of human data, when their original source are surveys made by official agencies or private firms under specific external regulations with due guarantees. An ethics approval was not required for this secondary analysis of the data, as per the authors' institutions and national regulations.

\section{Results}

Longitudinal changes. We considered first the profiles of the variable National Identity Feelings (Sense of Belonging) along the whole period, 2006-2019 (see Fig. 1). This is a qualitative variable with six distinct values: Only Spanish (Spn), More Spanish than Catalan (Spn>Cat), Equal Spanish than Catalan (Spn=Cat), More Catalan than Spanish (Cat>Spn), Only Catalan (Cat) and DK/NA (do not know or no answers). Percentages were estimated from 45 surveys over the period 2006-2019 on samples of sizes between 2500 and 1500 persons (one survey, at 2017, with 1338 only), with a total number of 88.538 respondents. In all, there was a total increase of 13 percentage points of those who feel 'only Catalans' and a fall of 7 percentage points of Catalan citizens who feel 'equal Catalan than Spanish', signaling a substantial variation towards decreasing the relevance of dual CatSpanish National Identity feelings. Such variations (Fig. 1) attained magnitudes that clearly exceeded 15 percentage points at some points, on both directions, along the whole period.

The more remarkable facts in Fig. 1 are the changes that arise in around 2012 on the size of two critical segments defined by this
National identity feeling variable. In that year, the dual national identity group 'Equal Spanish than Catalan' initiates an abrupt descend to nearly 17 percentage points (not yet recovered), while single national identity feeling group 'Only-Catalan' initiates an abrupt escalation of roughly 20 points (not yet reversed). Such a change in groups that are critical for cohesion of the whole society call for further inspection involving other variables.

To deepen the analysis, we studied National Identity Feelings in different population segments, obtained through another qualitative variable: Family/Mother language (surveys used slightly different questions to address that, along the period, see SI Appendix). This is a qualitative variable whose main values are either Catalan language or Spanish language that represented the $34.9 \%$ and $57.3 \%$ of the total population respectively, at the last survey studied, July 2019 (see Fig. 2). The remaining cases were people who answered both Spanish and Catalan languages as family/mother languages. They represented $4.1 \%$ of the population at the last survey. Other cases were negligible.

The small group whose family/mother language was 'Both' (Spanish and Catalan), exhibited an intermediate behavior, so its graph has been omitted for the sake of brevity. For the Catalangroup (family/mother language), the detected change points (considering profiles of all sense of belonging feelings) appeared between the second and the third CEO 2010 Barometer (as a decimal number approx. 2010.4), and the second and third CEO 2012 Barometer (as a decimal number 2012.65). For the Spanishgroup (family/mother language), the detected change points (considering also profiles of all sense of belonging) were between the second and the third CEO 2011 Barometers (as a decimal number 2011.65), and the second and the third CEO 2013 Barometers (as a decimal number 2013.7). The more striking changes appeared within the Catalan-group (as defined by family/ mother language), in particular around the regional elections of 25th Nov. 2012.

The marks in these plots signal events that might have been relevant to understand the evolution of the variables along the period (see Methods). The crucial change points detected by the

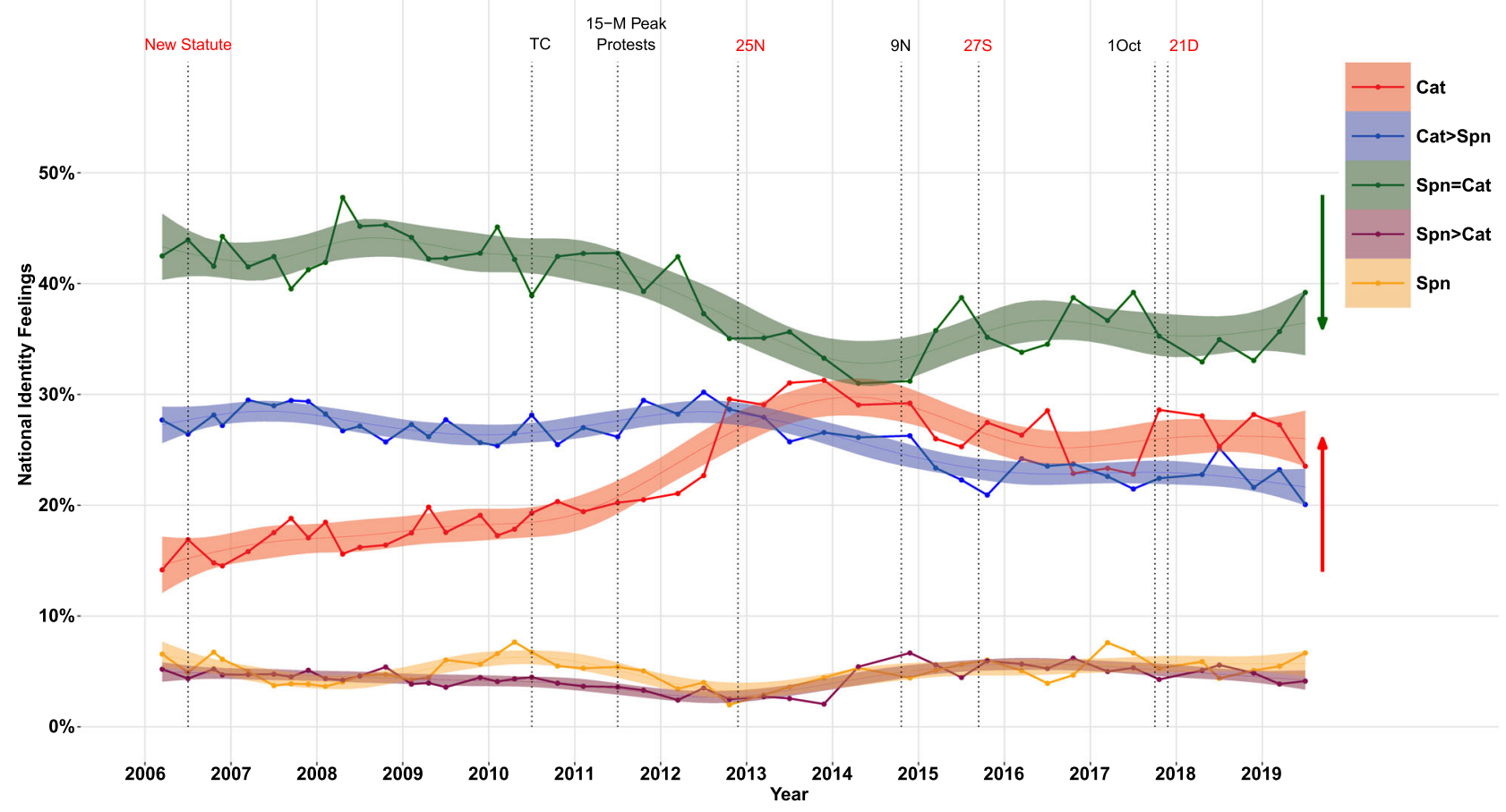

Fig. 1 Longitudinal changes of National Identity Feelings across the period 2006-2019, for all Catalonian population. Each band shows the evolution of proportions for each national identity feeling (percentages) across the whole period. DK/NA omitted. Bands based on $95 \%$ smooth confidence intervals. 

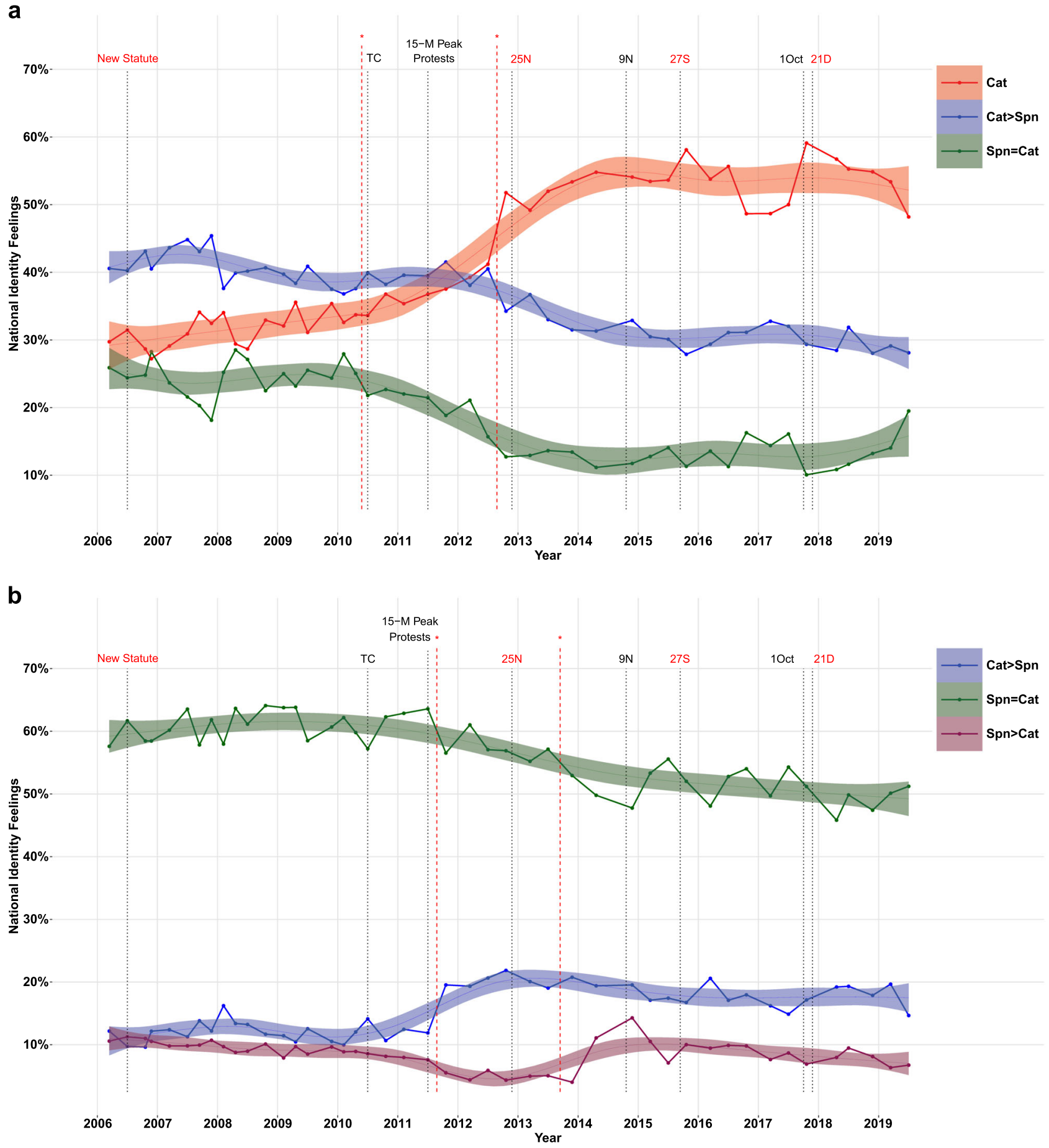

Fig. 2 Longitudinal changes of National Identity Feelings, across the period 2006-2019, depending on language segmentation. Two Catalonian population segments are considered. UP: a refers to citizens with Family/Mother language Catalan (at July 2019 survey: $34.9 \%$ of all Catalonian population). Down: b refers to citizens with Family/Mother language Spanish (at July 2019 survey: 57.3\% of all Catalonian population). Bands based on 95\% smooth confidence intervals.

package ecp, as explained above, were marked as red lines within the plots.

The effects of following news on public regional media. To obtain a more detailed picture of the evolution of sense of belonging in the main linguistic groups we analyzed the relevance of another variable constructed taking into account the answers of following the news either through regional public media (TV or radio that broadcast exclusively in Catalan language) or through other media. This variable, which will be referred as News, is dichotomous reaching only two possible values: Regional or Other. We directed our focus (see Fig. 3) to the sense of belonging 'Only Catalan' for the Catalan-group (as defined by family/ mother language) and for the Spanish-group (also defined by family/mother language).

There were abrupt changes in the sense of belonging 'Only Catalan' along the period, clearly dependent on their family/ 


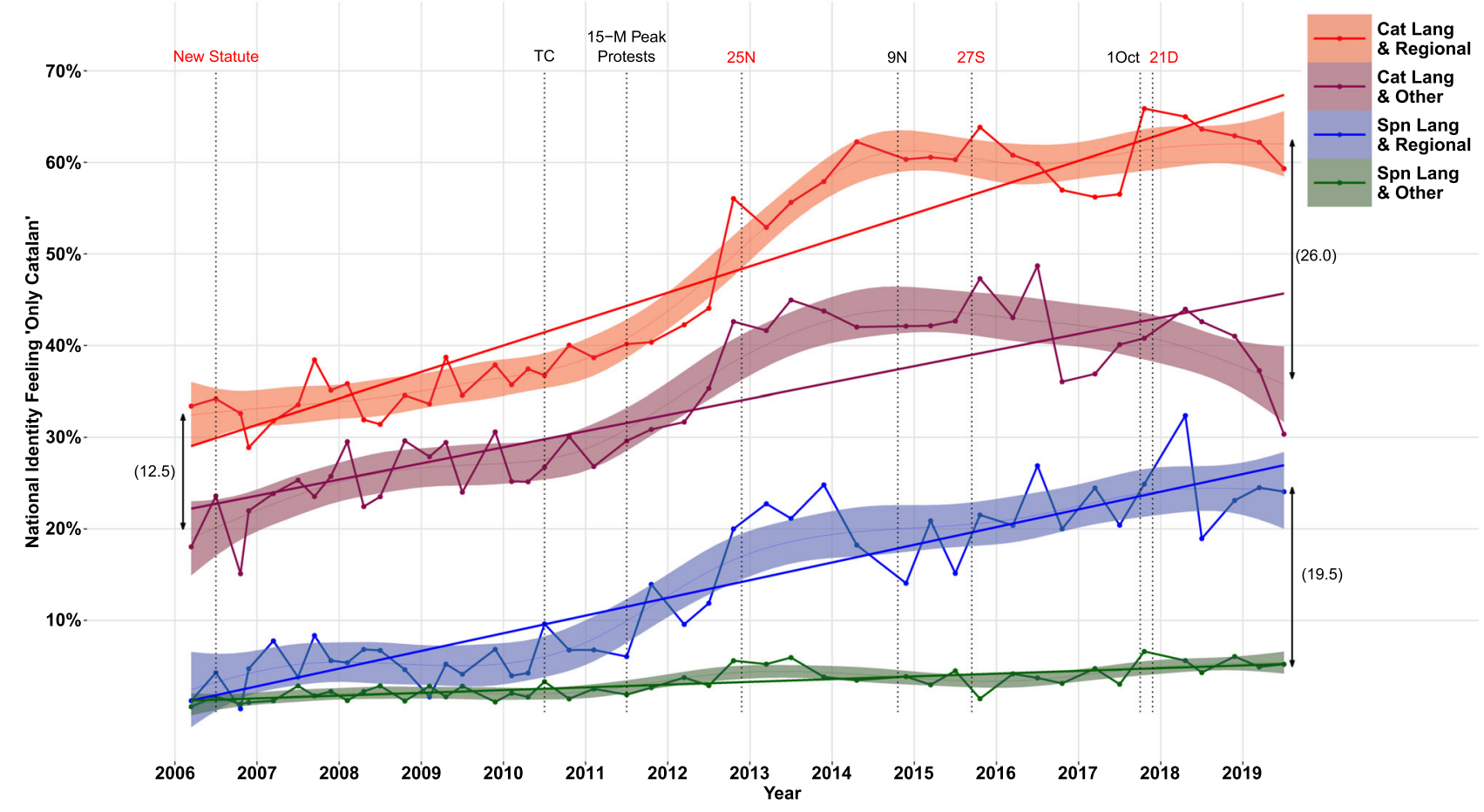

Fig. 3 Longitudinal changes of the National Identity Feeling "Only Catalan" across the period 2006-2019, depending on language and media news segmentations. The size of this identification type went from 14.2\% of all Catalonian population at March 2006 survey, up to $23.5 \%$ at July 2019. The four bands correspond to the four citizenry segments obtained crossing the two main categories of Family/Mother language (Catalan vs. Spanish) with the binary variable News (Regional vs. other), depending on whether the news are followed in regional media or not. Bands based on 95\% smooth confidence intervals. The fitted lines, one for each group, is a linear model fit. Observe the contrast between the biggest group (Family/mother language Spanish, not following news on regional media: $44.8 \%$ at last survey, in green), and the Family/mother language Catalan group who followed news on regional media (21.5\%, at last survey, in red). Notice also the different slopes of regression lines indicating distinctive trends. Moreover, the regression lines corresponding to Spanish language subgroups (green and blue) intersect around the year 2006 and we may conjecture, by extrapolating, that the Catalan subgroups (red and purple) should have had a similar behavior in a recent past, around the year 2000. The sizes of blue and purple segments were smaller: $12.5 \%$ and $13.4 \%$, respectively, at last survey.

mother language but also dependent on having been exposed to follow the news in regional public media or not (Fig. 3). The relevance of these where examined through a standard Analysis of Covariance. The dependent variable is the percentage of sense of belonging 'Only Catalan' considering a factor Group (four levels) and Time (year) as a covariate. The Group factor and the interactions were highly significant (see SI). Furthermore, comparing the slope of the regression lines, we find that all the slopes are significantly different with the exception of the slopes of two groups: family/mother language Spanish who follow news in public regional media and family/mother language Catalan who follow news in other media; all the other levels exhibit highly significant different slopes ( $p$-values obtained by Tukey method less than 0.0001). See Table SI-2 for more details.

The same analysis of covariance is repeated considering as a dependent variable the percentage of sense of belonging 'Equal Spanish than Catalan' (see Fig. 4), with the same factor Group and Time as covariate, as before. The effects of Group factor and the interactions were highly significant (see SI). Moreover, comparing the slope of the regression lines, we can get the different effects of media at the four levels of Group factor. Notice that with the exception of the slope between both family/mother language Catalan subgroups, all other levels exhibited very significantly different slopes ( $p$-values obtained by Tukey method less/equal than 0.0061 , most of them less than 0.0001). See Table SI-4 for more details.

To complete the analysis, we considered both dependent variables simultaneously (MANCOVA), obtaining that both Group factor, the covariate Time and the interactions were highly significant (see also SI).
2D dynamic profile diagram. The four subgroups obtained by distinguishing family/mother language (Catalan vs. Spanish) and whether news were followed in regional public media or otherwise, are represented in different colors and letters (see Fig. 5 and SI). At a particular time (a survey), each group is represented as a colored point in the 2D-plot, whose position indicates the profiles of Sense of belonging feelings corresponding to this group. The evolution of each group through time is explicitly showed joining the consecutive points of the group resulting in a continuous colored broken line in the 2D-plot. Relevant dates in the period 2006-2019 are also indicated, with the $25 \mathrm{~N}$ event (2012) marked in black. To correctly interpret the plot, different National identity feelings are also represented simultaneously as points in magenta color, with arrows indicating that if we move closer to these points, the corresponding identity feelings increase, since these arrows are the projection of the gradient vector field of the maps $\left(p_{1}, \ldots, p_{6}\right) \mapsto 2 \sqrt{p_{i}}$ at some convenient points near the point which corresponds to a population segment with $100 \%$ of people with the $i$-th identity feeling. The length of these arrows also depends of projection: the longer the arrow, the more important will be the role of the corresponding variable to interpret group variability.

As can be seen adding the \% of explained variance of the $x$ and $y$ axis of the graph $94.1 \%$ of the total variability is well represented in this 2D-plot. Notice also that the evolution of three of these four groups evolved similarly by increasing their national identity feelings 'Only Catalan' and 'More Catalan than Spanish', or decreasing the feeling 'Equal Spanish than Catalan' (Catalan or Spanish linguistic subgroups following news through public 


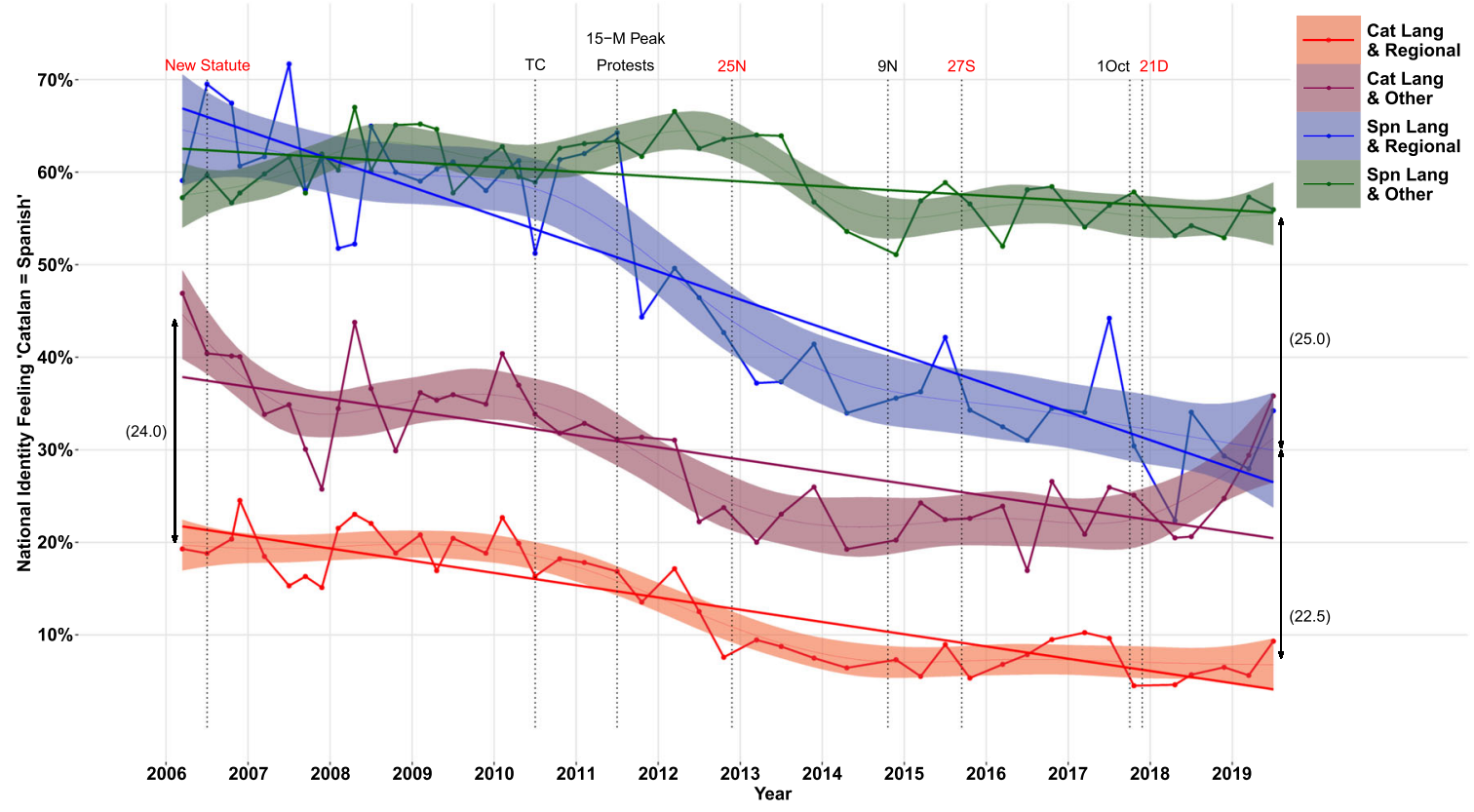

Fig. 4 Longitudinal changes of the National Identity Feeling "Equal Catalan than Spanish" across the period 2006-2019, depending on language and media news segmentations. The size of this identification type went from 42.5\% at March 2006 survey, to 39.2\% at July 2019. The four bands correspond to the four citizenry segments obtained crossing the two main categories of Family/Mother language (Catalan vs. Spanish) with the binary variable News (Regional vs. other), depending on whether the news is followed in regional media or not. Bands based on $95 \%$ smooth confidence intervals. The fitted lines, one for each group, is a linear model fit. Observe the contrast between the biggest group (Family/mother language Spanish, not following news on regional media: $44.8 \%$ at last survey, in green) and the Family/mother language Catalan segment who followed news on regional media (21.5\% at last survey, in red). They exhibited the highest difference. The biggest trend slopes differences occur when comparing the Spanish segments (green and blue). Notice that dark green and blue lines intersected at 2008, indicating that around this year both groups behaved similarly with respect to the dependent variable. The sizes of blue and purple segments were smaller: $12.5 \%$ and $13.4 \%$, respectively, last survey.

regional media). The Spanish group (family/mother language) who did not follow the news through the public regional media (approx. $44.8 \%$ of the population, at July 2019), was an exception of this radicalizing trend. This group, after a small oscillation between 2012 and 2013 (closer in time to 25N event, 2012), returned almost to its initial position. In the remaining groups the central and remarkable position of $25 \mathrm{~N} 2012$ event, is clearly visible, to the point of an apparent delimitation of two clusters within each group. Groups B and C appear to be moving, lately, towards their initial positions.

Similar plots were built for preferred political-territorial link with Spain, to analyze the evolution of preferences about political ties between Catalonia and Spain (See SI Figs. SI-1, SI-2).

\section{Discussion}

Our analyses focused mainly on "Sense of belonging" (National identity feelings) since it is a variable which (a) has been present invariably in all CEO surveys and (b) has shown dramatic changes along the secessionist surge (the so-called "el procés") (Amat, 2015; Barrio and Field, 2018; Coll et al., 2018; Elliot, 2018). As argued above, the eruption of the secessionist campaign delimited two periods: long and stable previous decades when dual-national identity (Sense of belonging: Equal Catalan than Spanish) was dominant and worked as an amalgamating factor for Catalonian society (Amat, 2015; Elliot, 2018); and the current one, when an abrupt polarization lead the citizenry into antagonistic and confronted blocks, one formed by those with singleidentity Catalan (dominant on the secessionist field), and a second one where dual-identity Cat-Spanish prevails (dominant on the unionist field).
By exploiting the microdata of the whole series of repeated CEO surveys, Fig. 2 displays a fundamental finding. It shows the evolution of Sense of belonging (National identity feelings) differentiated into two main citizenry segments: family/mother language Catalan versus family/mother language Spanish. For the first one there was a striking variation in a short period: an intense erosion of the dual-identity ( $S p n=C a t$, at Figures) and an intense increase of the single-identity Only Catalan. Note that, in this segment, the single-identity Only Catalan scaled approximately 30 percentual points in less than eight years. To our knowledge, there are no other examples of such dramatic changes in national identity within a stable Western society, in such a short period. In contrast, for the segment family/mother language Spanish, the dual-identity $(S p n=C a t)$ continued with nearly no erosion (neither we see appreciable variation towards the singleidentity Only Spanish). Figure 1 also documents the sudden change, around 2012, on national identity of two fractions, namely the "Equal Catalan than Spanish" and "Only Catalan", two population segments that are likely to contribute with cohesion or division, respectively, within the whole society. The outstanding feature of Figs. $2 \mathrm{a}, \mathrm{b}$ is the detailed dissection of such important variations, documenting the differences in the evolution of sense of belonging among these two segments.

This statistical evidence, supported by more than 45 surveys amounting to 88.538 observations is striking, given the extended previous period in which no moves were seen on this key, national identity variable (Tormos et al., 2014; Barrio and Field, 2018). It is worth noting that the change introduced by CEO, at 2011, asking for 'childhood or maternal language' instead of 'family language' may have had some consequences, although they were not apparent at all in the observed series. Cultivation of 


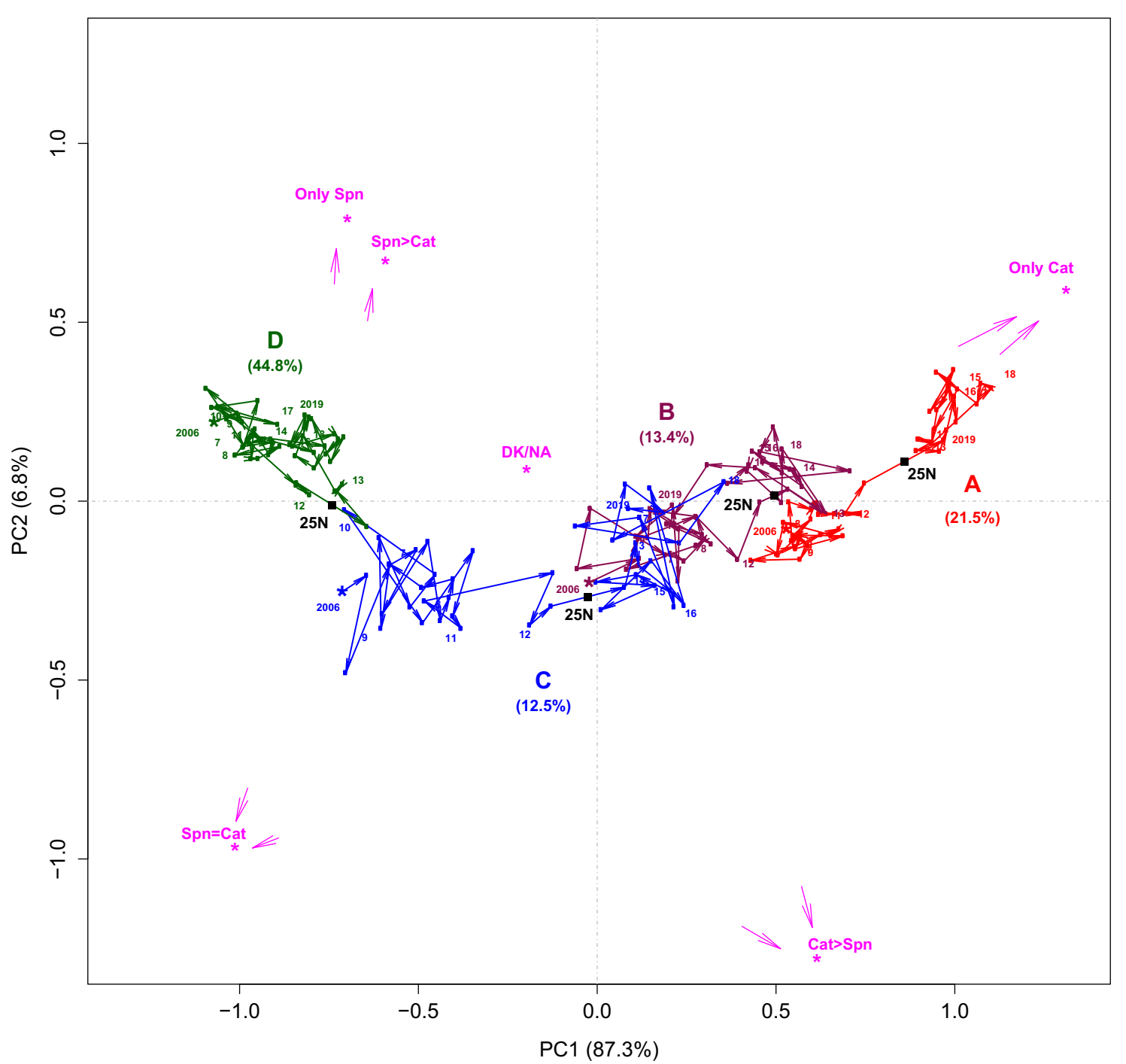

Fig. 5 2D-Dynamic Profile Diagram of National Identity Feelings across the period 2006-2019. For the four citizenry segments obtained crossing Family/ Mother language (Catalan vs. Spanish) and News (following news on public regional media or not). Group A (red): Family/mother language Catalan, following news on regional media (21.5\% at July 2019 survey); Group B (purple): Family/mother language Catalan not following news on regional media (13.4\% at July 2019 survey); Group C (blue): Family/mother language Spanish, following news on public regional media (12.5\% at July 2019 survey); Group D (green): Family/mother language Spanish not following news on regional media (44.8\% at July 2019 survey). This diagram summarizes the evolution of identity profiles for each colored group (24 series of respondent answers coming from 45 surveys, 2006-2019) in a mathematical space in which each point represents the percentages of National Identity Feelings within a group. Notice that Groups A-C suffered a clear displacement in the space of National Identity Feelings pre and post 25N regional elections (November 25th, 2012), in the sense of a greater polarization ('Only Catalan' feeling increases when we move to the top-right of the diagram). Group D exhibited a small movement near the event of $25 \mathrm{~N}$, but returned to its original position at present. Notice that this group is the biggest one (44.8\%, last survey: July 2019). This is a two-dimension reduction with quality of representation of $83 \%$ in the $x$-axes and $6.8 \%$ in the $y$-axis (overall, a quality of representation of $94.1 \%$ ).

double or multilayered national identity feelings has been argued to be preventive for societies harboring unsealed ethno-cultural frontiers, whereas promoting single-identity national feelings, either only Catalan or only Spanish in this case, can be a source of social unrest and potentially serious confrontations (Horowitz, 2001; Esteban and Ray, 2008; Esteban et al., 2012). In consequence, it may be wise to invest resources promoting doubleidentities.

Figures 3, 4 show that following Regional public media (TV and Radio) under control of Regional Government (both broadcasting in Catalan language, exclusively) correlated with a higher polarization around the issue of secession in the main language segments, family/mother language Catalan and family/ mother language Spanish, with some differences. Concerning the first group, the results are compatible with the hypothesis that a good number of people with family/mother language Catalan rely above all on the regional public media (Garcia, 2013; Tobeña, 2017; Oller et al, 2019a, 2019b) which additionally, broadcast exclusively in Catalan language. A good part of the segment with family/mother language Catalan follows political news through these regional public media (it accounts for approximately $21.5 \%$ of overall population, at the last survey) and they can become disseminators themselves through family/friends networks. This may explain why the group with family/mother language Catalan that do not follow news in the regional public media is also affected (it accounts for approximately $13.4 \%$ of overall population, last survey), albeit in an attenuated way: the growth rate of 'Only Catalan' identity feelings was approximately $2 / 3$ of the 
growth rate of those who follow regional public media. The key factor is the trust on media that everyone view as 'familiar' within these two segments. Notice the contrasting evolution of red (regional public media) vs. purple (other media), for the family/ mother language Catalan group at Figs. 3, 4.

Concerning the second group, family/mother language Spanish two facts deserve attention. First, the segment who follow news through public regional media (it accounts for $12.5 \%$ approx. of overall population, last survey) changed their identity feelings in the same direction as the group with family/mother language Catalan. However, the family/mother language Spanish segment who does not follow news through public regional media (accounting for $44.8 \%$ approx. of overall population, last survey) remained stable, without appreciable changes. Secondly, there was an absence of significant polarization at the opposite national Identity 'Only Spanish'. This fact is compatible with the conjecture that public regional media were a source of polarizing inputs, as the remaining media, which broadcast to all Spain, have not paid as much attention to regional political crises despite its relevance at particular moments. Figure SI-S4 (see SI) shows the absence of intensification of National identity feelings in the citizenry segment who follow news in Spanish generalist TV channels broadcasting to all of Spain (it accounts for approximately $32.9 \%$ of overall population, last survey), independently of their family/mother language.

Notice the contrasting evolution of blue (regional public media) vs. dark green (other media), for the family/mother language Spanish group at Figs. 3, 4. The evolution of identity feelings shown at these Figures, where we interacted family language with preferences for following Regional media, raises suspicions about the persuasive role played by the contents of public TV and Radio controlled by Autonomous powers. We must highlight the fact that the narrowing and intensification on National identity feelings only occurred in the segment with family/mother language Catalan, whereas the segment family/mother language Spanish, larger in size, did not significantly evolved in the opposite direction, towards a 'Only Spanish' identity. This contributes to diminish the chances of an open conflict. The erosion of dualidentity feelings within these segments would be a loss of the amalgamating capital of a citizenry that shares the same territory (in Catalonia, this means usually face to face doors).

Two recognizable "turning points" signaled clear departures towards distinctive polarization profiles among those segments of Catalan citizenship subgroups. The first one appeared shortly before the sentence of the Spanish High Court, at 2010, modifying the Autonomy Statute that had been approved at 2006. A second and much more important one was the decision taken by the moderate nationalist party that had been leading the Regional Government, for decades, of adopting a secessionist agenda around autumn 2012. In his systematic comparison between the lawful and agreed Scottish bid for independence (preceding the 2014 referendum), and the unlawful and unilateral at Catalonia, Elliot (2018) identified the same "breaking points". Our plots show that the appearance of the first one contradicts the depiction of Catalonian secessionist push as an outrage reaction against the "deep grievance" of the sentence from High Spanish Court, modifying a few articles the 2006 new Statute of Autonomy that had been voted by a minority of citizens. Pro-secession polarization within a fraction of citizenry had already started before such sentence. This is compatible with the conjecture that the impact of the TC sentence about the new Home Rule was relevant mainly to the extent that it has been used, extensively, as a political weapon to invigorate secessionist activism and increase polarization ${ }^{5}$.

Much more decisive was, however, the period leading to the regional elections at 25th Nov 2012. Such elections marked, in fact, the definitive point of departure for the secessionist wave, when Catalonian President at that time (leading a moderate nationalist party) lose the majority at the Autonomous Parliament. From that moment onwards, parliamentary majority depended from various secessionist forces and the Government opted for secession from Spain as its dominant strategy (Barrio and Field, 2018; Elliot, 2018). Figure 2 illustrates how, around these elections, a segment of citizenry (formed mainly by those with family/mother language Catalan and reporting "only Catalan", as national identity), departed from a previous slowly rising tendency (Bertomeus, 2018a), towards an abrupt acceleration. Percentages peaked on the first (illegal) consultation about secession (9 Nov 2014), and the rising stabilized at high levels all along the struggle between Regional and Spanish powers that persist today. This segment displayed parallel trends on several measures: national identity feelings ("sense of belonging"); preferences for political links with Spain (opting for "independence"); and expressing support for secession on a hypothetic (and legal) referendum for self-determination (see SI1-SI2 Figures). Such narrowing of national self-identification linked to preferences for secession showed by this group of "Catalan-natives" mainly, was not mirrored in the other big segments of citizenry (those with either Spanish or both Catalan+Spanish languages as their family/mother language). These fractions tended to maintain their dual "CatSpanish" national identities without noticeable changes. Globally, our systematic results confirmed the outstanding polarization around the issue of secession that Llaneras (2017), Marí-Klose (2018), Bertomeus (2018), Guntermann et al. (2018), Rodón and Guinjoan (2019), and Maza et al. (2019) had already shown departing from a handful of surveying points or from electoral results.

Following or not the news on Regional public media was an important mediator of changes on National identity feelings ("sense of belonging") and for preferences for secession. The strong gaps on media following preferences (news and political debates) based essentially on family-language divisions, surely contributed to exaggerate distinctive communal affections and frames of reference at both sides of the ethnolinguistic frontier: Catalans vs. CatSpanish. TV channels, newspapers and broadcasting stations which are directly or indirectly under control of the Regional Government not only dominated but fully encapsulated the secessionist audiences operating only or mostly, in Catalan language. This represents an obvious mismatch as Spanish is the language of daily use of more than half of Catalan citizens, thus reflecting the operation of a "communication bubble" that nourished the secessionist fraction: middle class natives and assimilated citizens who use Catalan language almost exclusively, in their daily routines and get their political opinion mainly from regional/local media (Barrio and Field, 2018; Coll et al., 2018; Miley, 2007, 2013; Crameri, 2014, 2015; Tobeña, 2017a; Rodon and Guinjoan, 2018). Despite unsolved discussions on the relative power of media to modify social opinion, there is agreement on their influence upon segmented audiences (Quattrociocchi et al., 2011, 2014, Shoemaker and Stremlau, 2014).

Before the dawn of secessionist surge, Miley (2007) established the existence of divergent modes of national identification across the main segments of Catalan society that depended on an ethnolinguistic frontier. Departing from $\mathrm{CIS}^{6}$ surveys and other social data, he challenged the depiction of Catalonian nationalism as a form of "civic nationalism." He showed that Catalan society contained an ethnolinguistic cleavage that distinguished selfidentification of two main population segments: "native, Catalan speaking" citizens and their Spanish-speaking neighbors with immigrant origins from other parts of Spain. "Mother tongue" had, in fact, the strongest impact upon an individual's selfidentification as predominantly Catalan vs. predominantly 
Spanish o mixed "CatSpanish" identities. In subsequent studies, Miley (2013) showed that there was a gap between political preferences of wide segments of citizenry and those of their representatives at the Autonomous Parliament: the language policy implemented by Regional powers was inconsistent with preferences of Spanish-speaking citizens. He identified, moreover, two mechanisms that blocked their representation into the Region's institutions: (1) a clear under-representation of those citizens in the Autonomous Parliament; and (2) a partial assimilation of some Spanish-speaking elected politicians into the attitudes of Catalan-speaking rulers. He concluded that the social bases of support for Catalan nationalism were "overwhelmingly ethnic" and that the movement was an elite-led, "top down" project. The present findings add likelihood to that hypothesis, since we see that the ethnolinguistic factor is highly associated to distinctive polarization during the secessionist surge. Divergent polarizing profiles associated also to differential exposures to the media under control of Regional powers.

Boylan (2015) had already shown, that national identity (being Catalan native or assimilated) was a much stronger predictor of the desire for secession, than perceived grievances resulting from an unfair fiscal treatment or other economic and political factors (analyzing CEO surveys, 2011-2013). Applying different statistical methods both Bel et al. (2019) and Romero-Vidal (2019) have emphasized the inability of important contextual factors to explain the surge and maintenance of Catalonian secessionist push: neither the impact of the deep economic crisis between 2008-2013 or the evolution of preferences for policy attitudes at the Region, along the whole period 1991-2018, were able to convincingly explain the appearance of intense and sustained demands for full sovereignty. In this regard, the present findings may represent an initial step for more extensive and fruitful approaches to an unexpected and mostly not yet explained secession crisis.

The highest achievement of the secessionist movement was the creation of an intense devotion for the goal of Catalonian independence, to the point of carrying the emphatic characteristics of a collective romantic passion that engaged an impressive segment of citizenry (Tobeña, 2017a). Such passion hardly enticed, however, the rest of Catalan population. The ingroup self-glorification ingredients conveyed by such nationalistic passion excluded, by definition, other actors within the region (Roccas et al., 2006; Leidner et al., 2010; Waytz et al., 2014). Fulfilling a dream for reaching full sovereignty by agreed and democratic pathways requires a clear majority, but Catalan secessionists appeared convinced that they deserved a swift and easy separation from Spain on the bases of a tiny parliamentary (non-social) majority. This belief might perhaps derive from "collective narcissism" (Golec de Zavala et al., 2009, 2019), a propensity that amounts to a conviction in the greatness of one's group accompanied by demands of external validation. Those narcissists typically demand privileged recognition and treatment, not equal rights. Recent findings indicated that national collective narcissism mediated voting behavior in the Unites States: besides intense partisanship (Mason, 2018), this trait was a main factor predicting Trump victory in the 2016 US election (Golec de Zavala et al., 2017). Collective narcissism also mediated Brexit 2016 vote, at UK (Federico and Golec de Zavala, 2018), along with other cognitive mediators (Zmigrod et al., 2018). Specific studies on this issue would be required that should encompass not only Catalonian secessionists but also people from recently reactivated pockets of Spanish nationalism.

The lack of a social majority behind the secessionist push opened apprehensions that had been tampered for decades (Amat, 2015, 2017; Coll et al., 2018; Crameri, 2014; Elliott, 2018), and it is hard to foresee pathways to defuse current tensions. The pressure applied by the secessionist field included many forms of contextual intimidation to keep silent the majority of citizenry (Barrio and Field, 2018; Morel, 2018; Tobeña, 2017a, 2018). Our findings indicate that family language has worked as a dividing line but also as a protective umbrella to preserve a mixed CatSpanish national identity, during a period of relentless social pressure coming from secessionist activism and local media. Other types of social influence were used extensively, with the aim of deepening political polarization. A large-scale analysis provided solid evidence that during the 2017 illegal "referendum" for Catalonian independence, analyzed as a case study, social bots generated and promoted violent content, aimed mainly at the secessionist population segment (Stella et al., 2018). Nearly 4 million Twitter posts, on that issue, generated by almost 1 million users were monitored and analyzed during two weeks around such event. The findings clearly indicated that automated social hacking contributed to exacerbate a severe political conflict.

In conclusion, the present findings showed that an ethnolinguistic cleavage based mainly on family/mother language (Catalan vs. Spanish) worked as a dividing line for a serious political confrontation between secessionists and unionists. This is the first complete quantitative analyses of the distinctive evolution of National identity feelings among those population segments, during the period 2006-2019. The findings underscore the crucial role played by media influence to accentuate political polarization and partisanship around the issue of secession. They provide a workable example of how ethnolinguistic frontiers can be used as fracture line for divisive conflict within an advanced, open and democratic European context. We suspect that there are still political avenues to be pursued, with the aim of preventing the conversion of the ongoing secessionist challenge, in Catalonia, into a chronic and intractable ethno-political conflict. Departing from objective and thorough statistical data could be, perhaps, a good starting point for giving chances to encompassing instead of divisive and dangerous polarizing policies.

\section{Data availability}

As already stated our primary data are public and easily accesible at CEO web (Centre d'Estudis d'Opinió, http://ceo.gencat.cat/). In addition to the data provided both at Main Text and SI sections, many other analytical and graphic results were obtained for the period 2006-2019. In particular, all series of mosaic plots derived by crossing different pairs of variables. All of them can be supplied by the authors to interested readers on demand.

Received: 2 May 2019; Accepted: 29 October 2019;

Published online: 26 November 2019

\section{Notes}

1 We use the label "Unionists" to identify the citizenry who is against secession, for practical reasons. This label permits an immediate understanding of the opposing postures. We are fully aware that some anti-secession forces prefer the term "Constitutionalists" or "Non-secessionists" because "Unionism" carries, in Catalonia, a deprecating tone and can be used as an insult during hot political debates.

2 Catalan language is mandatory, as first language, at primary school and most of high school (See: "Usos lingüístics de la població de Catalunya: Enquesta 2013, Generalitat de Catalunya: Departament de Cultura, http://llengua.gencat.cat/web/.content/ documents/publicacions/altres/arxius/eulp2013_fullet.pdf.)

3 CEO (Centre d'Estudis d'Opinió, http://ceo.gencat.cat/).

4 Until summer 2011 the survey question explicitly asked for 'family language', after that for 'childhood language in the family', see more details at SI Appendix.

5 See SI and Oller et al. 2019b: a less technical essay directed to a general audience, on similar targets as the present one but involving a smaller data set and with more emphasis on economic aspects.

6 CIS (Centro de Investigaciones Sociológicas, http://www.cis.es/cis/opencms/ES/index html). 


\section{References}

Amat J (2015) El llarg procés: cultura i política a la Catalunya contemporània (1937-2014). Tusquets, Barcelona

Amat J (2017) La conjura de los irresponsables. Anagrama, Barcelona

Barceló-Soler J (2013) The battle for secession: Catalonia versus Spain. J Politic Inquiry 1:1-11

Barrio A, Rodríguez-Teruel J (2017) Reducing the gap between leaders and voters? Elite polarization, outbidding competition, and the rise of secessionism in Catalonia. Ethn Racial Stud 40(10):1776-1794

Barrio A, Field BN (2018) The push for independence in Catalonia. Nat Hum Behav 2:713-715

Bel G, Cuadras-Morató X, Rodon (2019) Crisis? What crisis? Economic recovery and support for independence in Catalonia, Regional Science Policy and Practice. https://doi.org/10.1111/rsp3.12236

Bertomeus O (2018) ¿Sigue Cataluña siendo "un sol poble"? Agenda Pública 3:5

Bertomeus O (2018a) El terratrèmol silenciós: relleu generacional i transformació del comportament electoral a Catalunya. Eumo Ed, Vic

Boylan BM (2015) In pursuit of independence: the political economy of Catalonia's secessionist movement. Nation Nationalism 21:761-785

Burbea J, Rao CR (1982) Entropy differential metric, distance and divergence measures in probability spaces: a unified approach. J Multivar Anal 12(4):575-596

Castano E (2008) On the perils of glorifying the in-group: intergroup violence, ingroup glorification and moral disengagement. Personal Soc Psychol Compass 2(1):154-170

Crameri K (2014) Goodbye Spain? The Question of Independence for Catalonia. Sussex Academic Press, Eastbourne

Crameri K (2015) Political power and civil counterpower: the complex dynamics of the Catalan independence movement. Nationalism Ethn Polit 21:104-120

Coll J, Molina I, Arias-Maldonado M (eds.) (2018) Anatomía del procés. Debate, Madrid

Cuadras-Morató X, Rodon T (2018) The dog that didn't bark: on the effect of the Great Recession on the surge of secessionism. Ethnic Racial Stud 1-20

Dowling A (2018) The rise of Catalan independence: Spain's territorial crisis. Routdlege, New York

Elliot JH (2018) Scots and Catalans: union and disunion. Yale University Press, New Haven

Esteban J, Ray D (2008) On the salience of ethnic conflict. Am Econ Rev 98 (5):2185-2202

Esteban J, Mayoral L, Ray D (2012) Ethnicity and conflicts: theory and facts. Science 336:858-865

Federico ChM, Golec de Zavala A (2018) Collective Narcissism and the 2016 United States Presidential Vote. Public Opin Q 82(1):110-121

Garcia C (2013) Strategic communication applied to nation building in Spain: the experience of the Catalan Region. Public Relat Rev 39:558-562

Golec de Zavala A, Cichocka A, Eidelson R, Jayawickreme N (2009) Collective narcissism and its social consequences. J Personal Soc Psychol 97:1074-1096

Golec de Zavala A, Guerra R, Simao C (2017) The Relationship between the Brexit vote and individual predictors of prejudice: collective narcissism, right-wing authoritarianism and social dominance orientation. Front Psychol 8:2023. https://doi.org/10.3389/fpsyg.2017.02023

Golec de Zabala A, Dyduch-Hazar K, Lantos D (2019) Collective narcissism: political consequences of investing self-worth in the ingroup's image. Political Psychol 40(S1):37-74

Griffiths RD, Guillén-Alvarez P, Martínez Coma F (2015) Between the sword and the wall: Spain's limited options for Catalan secessionism. Nation Nationalism 21:43-61

Guntermann E, Blais A, Lago I, Guinjoan M (2018) A study of voting behaviour in an exceptional context: the 2017 Catalan election study. Eur Political Sci, https://doi.org/10.1057/s41304-018-0173-8

Hastie T, Tibshirani R (1990) Generalized Additive Models. Chapman and Hall, London

Horowitz D (2001) The deadly ethnic riot. University of California Press, Berkeley

James NA Matteson DS (2013) ecp: R package Nonparametr Mult change point Anal Multivar data, arXiv 1309:3295, http://adsabs.harvard.edu/abs/ 2013arXiv1309.3295

Leidner B, Castano E, Zaiser E, Giner-Sorolla R (2010) Ingroup glorification, moral disengagement, and justice in the context of collective violence. Personal Soc Psychol Bull 36(8):1115-1129

Llaneras K (2017) El apoyo a la independencia tiene raíces económicas y de origen social, El País. https://politica.elpais.com/politica/2017/09/28/ratio/1506601198_808440. html

Lustick IS, Miodownik D, Eidelson RJ (2004) Secessionism in multicultural states: does sharing power prevent or encourage it? Am Political Sci Rev 98:209-229

Marí-Klose P (2018) Cataluña deshilachada: procesos de desintegración de una comunidad imaginada. In: Coll J, Molina I, Arias-Maldonado M (eds) Anatomía del procés. Debate, Madrid, pp 221-246

Mason L (2018) Uncivil agreement: how politics became our identity. University Chicago Press
Matteson DS, James NA (2014) A nonparametric approach for multiple change point analysis of multivariate data. J Am Stat Assoc 109(505):334-345. https://doi.org/10.1080/01621459.2013.849605

Maza A, Villaverde J, Hierro M (2019) The 2017 Regional Election in Catalonia: an attempt to understand the pro-independence vote. Econom Política 36:1-18

Miley ThJ (2007) Against the thesis of the "civic nation": the case of Catalonia in contemporary Spain. Nationalism Ethn Politics 13:1-37

Miley ThJ (2013) Blocked articulation and nationalist hegemony in Catalonia Regional Fed Stud 23(1):7-26

Minder R (2017) The struggle for Catalonia: rebel politics in Spain, London: Hurst and Co.

Morel S (2018) En el huracán catalán, Barcelona:Planeta

Oller JM, Satorra A (2017) Toward an index of political toxicity. BEIO 33 (2):163-182. http://www.seio.es/BBEIO/BEIOVol33Num2/index.html\#86

Oller JM, Satorra A, Tobeña A (2019a) Secessionists vs. Unionists in Catalonia: mood, emotional profiles and beliefs about secession perspectives in two confronted communities. Psychology 10:336-357. https://doi.org/10.4236/ psych.2019.103024

Oller JM, Satorra A, Tobeña A (2019b) Pathways and legacies of the secessionist push in Catalonia: linguistic frontiers, economic segments and media roles within a divided society, Policy Network Papers, Oct. (https://policynetwork. org/publications/papers/pathways-and-legacies-of-the-secessionist-push-incatalonia/).

Quattrociocchi W, Conte R, Lodi E (2011) Opinions manipulation: media, power and gossip. Adv Complex Syst 14:567-586

Quattrociocchi W, Caldarelli G, Scala A (2014) Opinion dynamics on interacting networks: media competition and social influence. Sci Rep 4:4938

Qvortrup M (2014) Referendums and Ethnic Conflict. University of Pennsylvania Press, Philadelphia

OEC Group (2017) La Cataluña immune al procès. SCC, Barcelona. https://www. societatcivilcatalana.cat/sites/default/files/docs/La-Cataluna-inmune-vf.pdf

Roccas S, Klar Y, Leviatan I (2006) The paradox of group-based guilt: modes of national identification, conflict vehemence, and reactions to the in-group's moral violations. J Personal Soc Psychol 91(4):698-711

Rodon T, Guinjoan M (2018) When the context matters: identity, secession and the spatial dimension in Catalonia. Political Geogr 63:75-87

Romero-Vidal X (2019) Two temperatures for one thermostat: the evolution of policy attitudes and suport for independence in Catalonia 1991-2018. Nation Nationalism. https://doi.org/10.1111/nana.12559

Serrano I (2013) Just a matter of identity?: support for independence in Catalonia Regional Fed Stud 23(5):523-545

Sidanius J, Feshbach S, Levin S, Pratto F (1997) The interface between ethnic and national attachment: ethnic pluralism or ethnic dominance? Public Opin Q 61(1):102-133

Shoemaker E, Stremlau N (2014) Media and conflict: an assessment of evidence. Prog Dev Stud 14(2):181-195

Sorens J (2005) The cross-sectional determinants of secessionism in advanced democracies. Comp Political Stud 38:304-326

Stella M, Ferrara E, De Domenico M (2018) Bots increase exposure to negative and inflammatory content in online social systems. PNAS 115:12435-12440. https://doi.org/10.1073/pnas.1803470115

Tobeña A (2017) Secessionist urges in Catalonia: media indoctrination and social pressure effects. Psychology 8:77-96

Tobeña A (2017a) La pasión secesionista: psicobiología del independentismo. EDLibros, Barcelona

Tobeña A (2018) Entrenched Catalonia: a secessionist venture trapped on an ethnopolitical draw. Psychology 9:460-471

Tormos R, Muñoz J, Hierro MJ (2014) Endogenous identities? How the independence debate is reshaping Catalans' identity. IBEI Workshop The Politics of Identity Adoption, Barcelona, http://www.cuimpb.cat/files/TormosMu\% C3\%B1ozHierro_EndogenousIdentities.pdf

Von Babel JJ, Pereira A (2018) The partisan brain: an identity-based model of political belief. Trends Cogn Sci 22(3):213-223

Waytz A, Young LL, Ginges J (2014) Motive attribution asimmetry for love vs. hate drives intractable conflict. PNAS 11(44):15687-15692

Wood SN, Pya N, Saefken B (2016) Smoothing parameter and model selection for general smooth models (with discussion). J Am Stat Assoc 111:1548-1575. https://doi.org/10.1080/01621459.2016.1180986

Zmigrod L, Rentfrow PJ, Robbins TW (2018) Cognitive underpinnings of nationalistic ideology in the context of Brexit. PNAS 115(19):E4532-E4540

\section{Acknowledgements}

Damián Gil M.D. provided the first script that permitted to build the database of the full series of CEO Barometers. OEC Group members provided lively discussions with suggestions that improved and helped to focus the present research. A.T. work was partially supported by AFOSR-MINERVA FA9550-18-0496 Grant and Bial Foundation Grant 163/14. 


\section{Competing interests}

The authors declare no competing interests.

\section{Additional information}

Supplementary information is available for this paper at https://doi.org/10.1057/s41599019-0357-z.

Correspondence and requests for materials should be addressed to A.T.

Reprints and permission information is available at http://www.nature.com/reprints

Publisher's note Springer Nature remains neutral with regard to jurisdictional claims in published maps and institutional affiliations. (c) (i) Open Access This article is licensed under a Creative Commons Attribution 4.0 International License, which permits use, sharing, adaptation, distribution and reproduction in any medium or format, as long as you give appropriate credit to the original author(s) and the source, provide a link to the Creative Commons license, and indicate if changes were made. The images or other third party material in this article are included in the article's Creative Commons license, unless indicated otherwise in a credit line to the material. If material is not included in the article's Creative Commons license and your intended use is not permitted by statutory regulation or exceeds the permitted use, you will need to obtain permission directly from the copyright holder. To view a copy of this license, visit http://creativecommons.org/ licenses/by/4.0/.

(C) The Author(s) 2019 